\title{
The International Society for Pediatric Neurosurgery: our mission under challenge
}

\author{
Rick Abbott
}

Published online: 8 July 2009

(C) Springer-Verlag 2009

The past 2 years have been two of the most memorable of my life. It was a humbling experience to be elected President-Elect at our Taipei meeting in 2006 and to then receive the poncho in 2007. And, it was a joyous experience to work with what has to have been one of the most talented and industrious executives in the history of the International Society for Pediatric Neurosurgery (ISPN). These are memories I will always cherish. I thank you for the honor of letting me work for an organization that is so good and that I care so much about.

In 1972, 11 neurosurgeons assembled in Chicago and agreed to form the ISPN. The energy for this stemmed from a belief that in order to insure a rapid evolution of our specialty, a sharing of the collective knowledge was mandatory. This type of communication has always been at the core of the ISPN's activities, and in 2000, our then president Hal Rekate led us in putting this mission on paper (Fig. 1).

Our mission is the promotion of health in our young patients. We are no different than other specialties caring for children. We are passionate to further our specialty, and the energy for this comes from our love of children and our desire to serve them well. We take time away from our families to study, we spend our money to travel to learn new techniques, and we sacrifice our time to educate others.

R. Abbott

Clinical Neurological Surgery,

Albert Einstein College of Medicine,

New York, NY, USA

R. Abbott $(\bowtie)$

Department of Neurological Surgery, Montefiore Medical Center,

111 E. 210th St,

Bronx, NY 10467, USA

e-mail: rabbott@montefiore.org
To accomplish these tasks, we have traditionally used our printed journals, annual scientific meeting, and educational courses held around the world. These tools were developed in response to the realities of the mid-twentieth century and have been very successful in driving the expansion of our specialty. The ISPN welcomes new members every year, and the attendance at our annual meeting continues to grow. The number and sophistication of the presentations at our annual meeting continues to expand. We are challenged by people such as Archbishop Tutu and the needs of emerging societies in Africa, Asia, and the Americas to support the development of pediatric neurosurgery in their communities. We need to congratulate ourselves on the great strides we have taken toward meeting our mission. But, before we do, before we sit back and reflect on our accomplishments, we had better take a good hard look at what is happening in our world. I do not need to tell you that it is rapidly changing. Therefore, I feel that it is timely for the ISPN to reflect on our mission and how we can support the needs of societies where our specialty is not fully developed.

When we look at our world, we are seeing a rapid equilibration in access to information. This has been due to the emerging world's rising capacity for wealth generation (Fig. 2) [1]. While for the past 400 to 500 years, a small handful of countries with relatively small populations dominated the world economy and controlled access to much information, this is rapidly changing as nations with massive populations experience staggering rates in the growth in their economies. India and China, the prime examples of these phenomena, have liberated much of their economies, and they now function in a largely free-market environment. The result is a freer access to information and the generation of wealth. The key here is the freeing of their economies from state control, and this lesson is being learned in other emerging countries such as Brazil and 


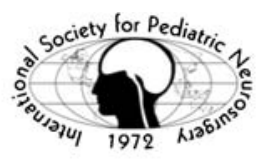

The International Society for Pediatric Neurosurgery (ISPN) seeks to promote the health of children throughout the world by encouraging the ethical transmission and exchange of neuroscientific information and techniques related to Pediatric Neurosurgery

Fig. 1 The mission statement of the International Society for Pediatric Neurosurgery

Mexico. We have seen an impressive increase in access to knowledge as these countries develop. And this is not an accidental by-product since there must be access to information for an industry to respond to the needs of the marketplace. The result for many individuals is a freer access to information and the wealth to purchase it. While the current turbulence in our world economy may slow this process, it will not reverse it so we can only expect the number of individuals with unimpeded access to information to grow.

We are experiencing a remarkable evolution in the ability to move vast amounts of information around our world almost instantaneously. In March of 1993, the worldwide web, as we know it, was introduced, and Fig. 3 shows the increase in domains and computers accessing the internet from 1993 to 1996 and compares these numbers to the current number of active domains and users of the internet $[3,4]$. An anesthesiologist pulled me into his office in 1993 to listen to him speak over the internet with a colleague in Australia. I rushed home and purchased a telephone modem to access the internet and spent many subsequent hours waiting for files to be downloaded. Now, 15 years later, I have data delivered into my home at a rate that is 400 times faster. I routinely review MRI scans of hospitalized patients on my home computer and speak with my son and daughter-in-law who live in Australia using free video teleconferencing technology of a quality equal to that of a routine phone call.

And this capability is not limited to a small number of individuals. Figure 4 shows some examples of the number of users of the internet in regions around the world [5]. The current reality is most people with some means can access the internet, and this access is improving by the month. Informational sites for the public began to be introduced in 1993 and are now routinely used by our patients. Increasingly, physicians are also gaining access to meaningful information. I have been able to search our National Institute of Health's PubMed site for reference articles for the past 10 years and can now download full articles from thousands of medical journals and textbooks [8].
The Congress of Neurological Surgeons has a fledging educational section that includes, among other things, a Wikipedia that readers, once logged on, can freely comment upon [2]. We can go to internet sites such as the NIH or the Children's Oncology Group to learn of treatment options for our patients $[6,7]$. Increasing numbers of us can access the radiographs of our patients over the internet. As our comfort level increases and our ability to access bandwidth in our work place improves, we will probably start to videoconference with each other about our patients, perhaps even while in our operating rooms.

The natural impact of this availability of information is a sense of empowerment on the part of the user. Now, when an individual is faced with a question, it is a relatively simple matter to obtain information and, thereby, an answer. Importantly, this process is happening using information conduits that are completely independent of governmental bodies and the traditional repositories of knowledge previously formed to serve as arbitrators of truth. We, as individuals, are gaining self-confidence, whether rightly or wrongly felt, in our ability to obtain, sift, and accept information as answers to our questions or problems in a timely manner. This is the case for both the lay public and professions. This is leading to a devaluation of the traditional institutions that in the past were relied upon for information. Will this lead to a cynicism and skepticism towards us? Or will we establish new relationships with each other, other professionals, and our patients based on a much more democratic access to information? Will individuals in society become self-sufficient in navigating their life and its problems? And what will become of the

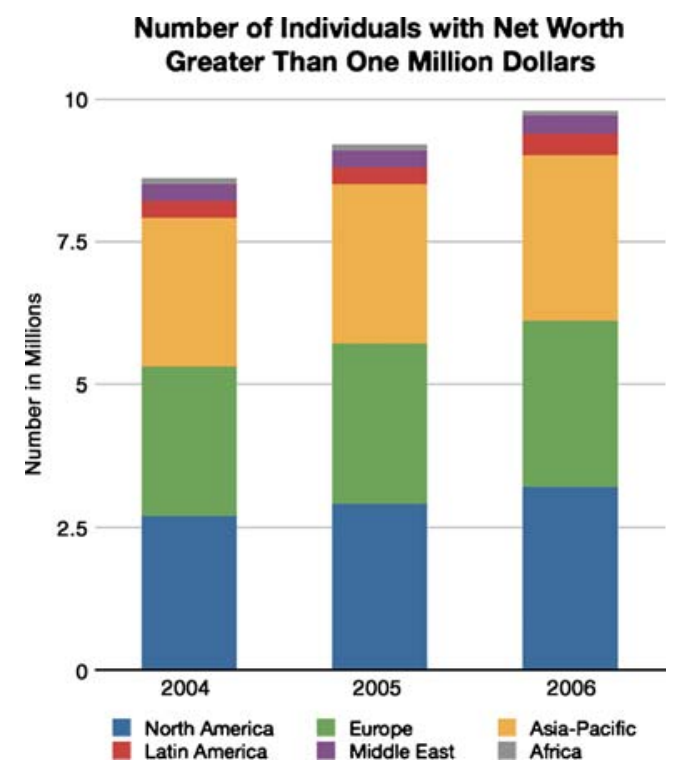

Fig. 2 Number of individuals whose net worth exceeds $\$ 1,000,000$ by the regions of the world. The growth in number for North America was $9.2 \%$, Europe $6.4 \%$, Asia Pacific 8.6\%, Latin America 10.4\%, the Middle East $11.9 \%$, and Africa $12.5 \%$ 
Fig. 3 Logarithmic growth in web domains and users (computers) on the internet from January 1993 to January 1996 and number for each in April 2009

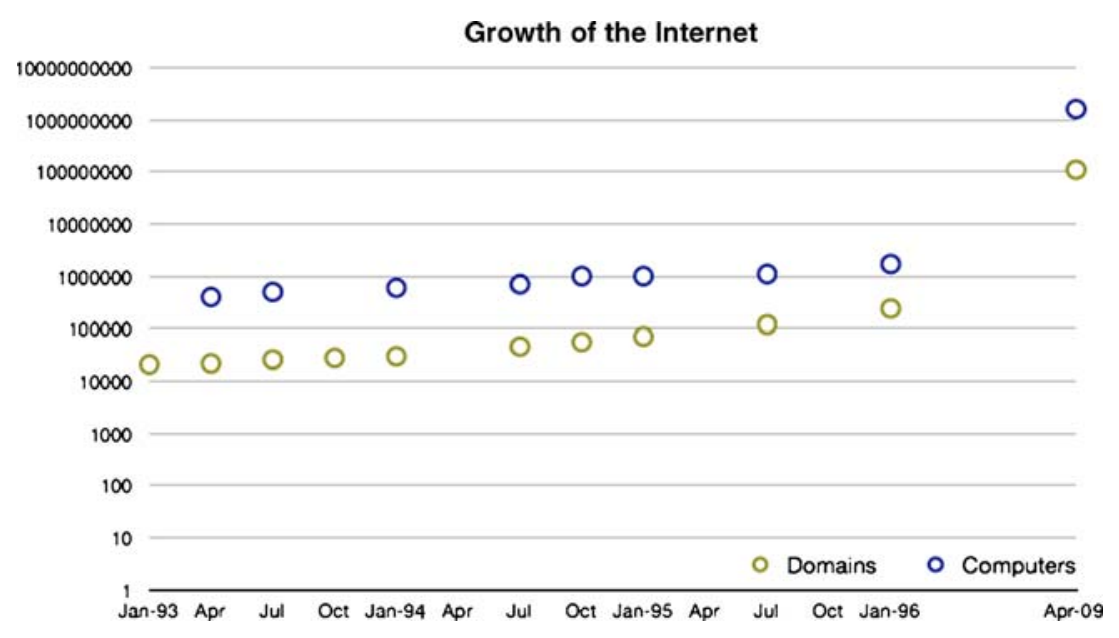

institutions we established to meet our needs when the flow of information was more constricted? In short, how will society validate the information it will be presented with?

While we may, as individuals, become increasingly competent in obtaining and sifting information in order to answer a particular question, I imagine that there will still be a need for organizations whose mission it is to certify and serve up information in a way that is factual, functional, and entertaining. While we can all cite examples of individuals who have used the web to establish blogs or have posted informational sheets that have become authoritative on a given subject matter, I suspect that this will not be the model for the evolution of knowledge and its dissemination in the future. The process is simply too laborious to expect a handful of individuals to assemble such information to the degree that it examines a topic in depth and then to maintain its currency. One can reflect on the effort needed to generate an oral presentation, a scientific paper advancing a new concept, or a chapter for a medical text to understand the effort involved. And these are relatively time-limited commitments in comparison to taking on the obligation of a teacher with a class of continuously new students and a subject that is continually changing. When I consider my experience, I quickly realize that all too often, there is a force outside of me-a professional society, educational institution, journal, or motivated student-that helps drive me in my efforts. I also realize the value of the peer review and editorial processes in validating the information provided to me. While these forces from our traditional institutions are currently under threat, they also have great value, and they are worth our efforts to evolve them to meet the new reality. We must work to maintain these relationships and institutions, modifying them to maintain their relevancy to the new reality of the free flow of information. The public will always need believable arbitrators of truth, and they will seek them out. If they are supplied with believable current information, then they will use the source.

When I recently asked a group of neurosurgical residents how they would prefer to obtain their information, they almost uniformly answered electronically. While they cited the enjoyment of holding a book, they prefer the increased control over their study by being able to read a summary digital article with hyperlinks from keywords allowing
Fig. 4 Number of internet users in December 2000 and April 2009 by regions of the world

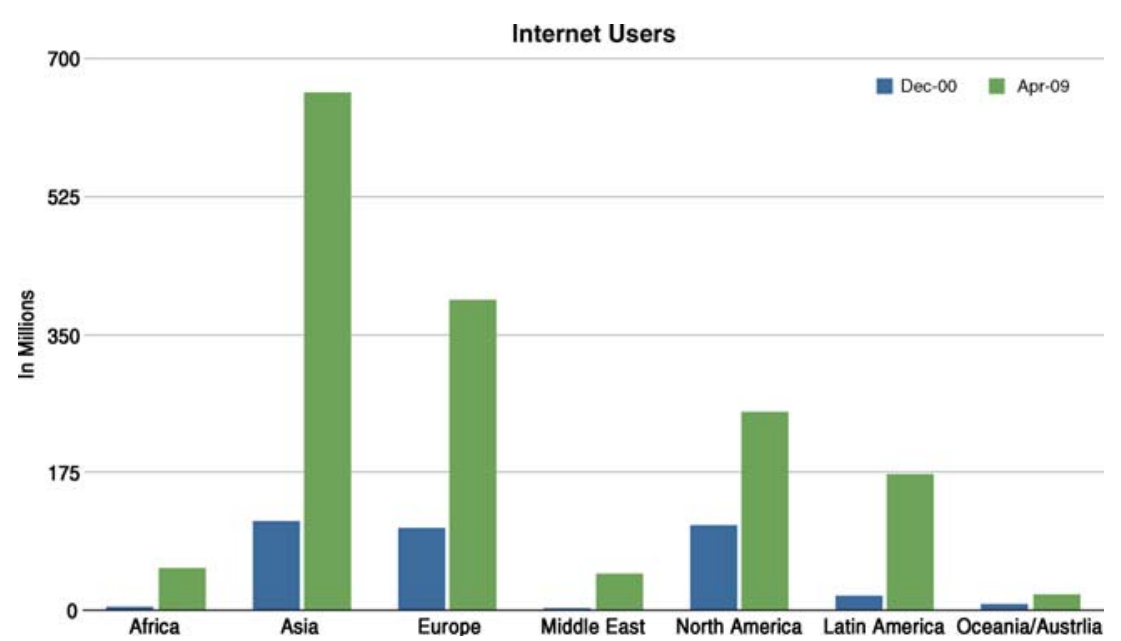


them to "drill down" on the information they needed to understand the central theme. In other words, they, and not the author, control the depth of their study. They could quickly review the portion of the subject they already knew and explore in depth that portion that they did not. They feel that this should optimally be augmented with video. All these elements allow a tailored experience that addresses the specific needs of the viewer. For example, a student could spend his or her time studying the pathophysiology and genetics of a condition in preparation for a test or view a video of a surgical technique in preparation for an operation the next day. A patient or family member could explore a topic to a depth that fulfills their needs. All these paths would be made available off a single master summary page. This sort of document or tool will revolutionize how we acquire information, as it will allow for immediate answering of a question to a depth that will be dictated by the reader. Just imagine the opportunity we have for our patients' understanding the condition afflicting them or for our trainees to understand the nuances of the case confronting them or for us to become aware of a new insight on treating a condition. The development of such an educational tool for pediatric neurosurgery will be a monumental task requiring the dedicated work of scores of us and the cooperation of all the pediatric neurosurgical societies of the world.

Our younger colleagues have a great deal of comfort for using teleconferencing technology to obtain information. Theirs is a visual generation use to obtaining information off the screen and conversing digitally. We are all familiar with the concept of teleconference as a teaching tool, but this is increasingly becoming available online. There are models available that allow the student to view conferences or classes on demand and then have a dialog with the lecturer. Continents can separate the teacher and student. The classroom becomes a tool controlled by the student's need for information, no longer a slave to the clock. Further, as teleconferencing becomes more robust, spur-of-the-moment student-teacher consultations will become a reality. The student no longer needs to adapt his or her work day to the lecture schedule and, when confronted with a question or problem, can easily consult one of a group of teachers with the aid of video to show the elements of the problem.

Clearly, the world's capacity to move data is now at the point where most countries can supply access to video streaming of acceptable quality. Most practitioners now have a comfort level in using the internet for the transfer of text information, be it email, scientific articles, or patient care information. Increasingly, we are gaining a similar comfort level for moving static graphical information such as radiographic images and still pictures. Within the next year or two, we will have a similar comfort for video including real-time video conferencing. As has happened over the past decade, you will see individuals and organizations step forward to exploit these capabilities and, by doing so, become the preferred source for information. They will become the new authority, and they will shape the agenda, be it how we think about a problem or what tools we use to manage the problem. We are seeing this in my country in our press industry. Increasingly, younger individuals in my society obtain their news from the internet. Our traditional press has been forced into having a presence on the internet in order to remain relevant, and every month papers retire their printed additions. Many are predicting the demise of printed papers within the very near future.

In short, our traditional means for spreading the knowledge of our specialty is under threat. Will our society continue to be successful in its efforts given all the forces that are in play? I suspect we will if the ISPN evolves to acknowledge that the means for delivering information is changing and that it might be radically different in tomorrow's world. Currently, the ISPN has a handful of tools that we use to address our mission. For the past two decades, the ISPN has had a model for responding to a region's need for increasing its capacity to handle pediatric neurosurgical patients. We have assembled a faculty to travel to the locale in need to deliver a didactic course on the state of art in pediatric neurosurgery. In many places, this has been very successful. India is the prime example of this, and we should all be very proud of our efforts there as she becomes the instructor, no longer just the pupil. This has been a 15-year plus project though. Do we continue at this pace, or do we explore other means? And is it costeffective to spend $\$ 30,000 /$ year to reach 150 to 300 students? Can our treasury sustain the effort as costs rise? Our journal's content continues to be of high caliber, and its impact grows. But will this printed material continue to be relevant in an age of sophisticated users of digital information? Our website remains available to us all, but how many of us return to it on a regular basis and for what reason? Does anyone else? Our largest tool for disseminating knowledge gained about our specialty is our annual scientific meeting. As I had previously stated, we have much to be proud of here. Our meeting is now second to none in its content and its intellectual stimulation. A physician needs to go nowhere else to gain an appreciation of what is occurring on our specialty's cutting edge. Unfortunately, our economy conspires against us. I anticipate increasing financial challenges for us to attend these meetings on a yearly basis. So, how much impact will it have on those who do not attend our meetings? These are all questions that I would like for you to ponder. Finding answers to these questions will frame the relevance of the ISPN in the twenty-first century.

For me, the response of our ISPN should be to acknowledge that this revolution is happening and to 
resolve that we will actively participate in it. This will mean not only that our society will need to create a vehicle that will deliver the information we wish to provide but also that we will need to do this without an "undo" burden on our member educators. We are pediatric neurosurgeons, not software engineers or full-time educators. Consequently, we will need wide participation by the Society's membership to share the work. Also, the Society will need to fund a process that will take the information our members provide and then deliver it in a fashion that speaks to the modernday user. As we become involved in this process, we will also need to liaison with the other medical organizations so that we can provide the best information in the most usable format at the most reasonable cost.

I am convinced that a real transformation is occurring in how we obtain and deliver information at all levels in each of our lives. I am also convinced that we, as a Society, must respond to this challenge if we wish to remain relevant in our specialty.

\section{References}

1. Angelicola, M., B. Beauvalot, et al. (2007) World Wealth Report. http:// www.ml.com/index.asp?id=7695_7696_8149_74412_79272_79918. M. Lynch and Capgemini. New York

2. Congress of Neurological Surgeons (2007) "University of Neurosurgery." Retrieved April 17,2009, 2009, from http://univ.cns.org/

3. DomainTools (2009) "Domain Counts \& Internet Statistics." Retrieved April 17, 2009, from http://www.domaintools.com/ internet-statistics/

4. Gray, M. (1996) "Internet growth: raw data." Retrieved April 17, 2009, from http://www.mit.edu/ mkgray/net/internet-growth-raw-data.html

5. Miniwatt Marketing Group (2009) "Internet World Stats; Usage and population statistics." Retrieved April 17, 2009, from http://www. internetworldstats.com/stats.htm

6. NationMaster (2003) "Internet statistics > international internet bandwidth $>$ Mbps (most recent) by country." Retrieved April 17, 2009 from http://www.nationmaster.com/graph/int_int_int_ ban_mbp-internet-international-bandwidth-mbps

7. NINDS (2009) "National Institute of Neurological Disorders and Stroke." Retrieved April 17, 2009, from http://www.ninds.nih.gov/

8. U.S. National Library of Medicine (2009) "PubMed." Retrieved April17, 2009 from http://www.ncbi.nlm.nih.gov/pubmed/ 